\title{
Potential-Assisted Adsorption of Bovine Serum Albumin onto Optically-Transparent Carbon Electrodes
}

\author{
Tomás E. Benavidez and Carlos D. Garcia* \\ Department of Chemistry, The University of Texas at San Antonio, One UTSA Circle, San \\ Antonio, TX 78249, USA
}

\begin{abstract}
This manuscript describes the effect of the applied potential on the adsorption of bovine serum albumin (BSA) to optically transparent carbon electrodes (OTCE). To decouple the effect of the applied potential from the high affinity of the protein for the bare surface, the surface of the OTCE was initially saturated with a layer of BSA. Experiments described in the manuscript show that potential values higher than $+500 \mathrm{mV}$ induced a secondary adsorption process (not observed at open-circuit potentials), yielding significant changes in the thickness (and adsorbed amount) of the BSA layer obtained. Although the process showed a significant dependence on the experimental conditions selected, the application of higher potentials, selection of $\mathrm{pH}$ values around the isoelectric point (IEP) of the protein, high concentrations of protein, and low ionic strengths yielded faster kinetics and the accumulation of larger amounts of protein on the substrate. These experiments, obtained around the IEP of the protein, contrast with the traditional hypothesis that enhanced electrostatic interactions between the polarized substrate and the (oppositely charged) protein are solely responsible for the enhanced adsorption. These results suggest that the potential applied to the electrode is able to polarize the adsorbed layer and induce dipole-dipole interactions between the adsorbed and the incoming protein. This mechanism could be responsible for the potential-dependent oversaturation of the surface and could bolster to the development of surfaces with enhanced catalytic activity and implants with improved biocompatibility.
\end{abstract}

\section{Introduction}

Understanding the adsorption of proteins to solid surfaces is a critical topic in a variety of fields (biomedical, food science, sensing, etc) because it can have significant consequences in the orientation, ${ }^{1}$ conformation, ${ }^{2}$ and biological activity of the adsorbed layer. Overall, the adsorption of proteins at interfaces is a spontaneous process that occurs almost every time a protein-containing solution contacts a solid surface. The adsorption is driven by short- and long-range forces resulting from a combination of electrostatic interactions between the protein and the sorbent surface, co-adsorption of small ions, dispersion forces, changes in the state of hydration of the sorbent surface and parts of the protein molecule, and structural rearrangements in the protein. ${ }^{1,3-5}$ The adsorption is therefore influenced by the characteristics of the protein (size, flexibility, and charge), the substrate (surface energy, charge, and morphology) and the environment (solvent, $\mathrm{pH}$, temperature, and ionic strength). As a result, examples highlighting the effect on protein adsorption as a function of

\footnotetext{
*To whom correspondence should be addressed. One UTSA Circle, San Antonio, TX 78249, USA. Ph: (210) 458-5774, Fax: (210) 458-7428, carlos.garcia@utsa.edu.

The authors have declared no conflict of interests.

7. Supporting Information Available

This information is available free of charge via the Internet at http://pubs.acs.org/.
} 
the characteristics of the protein, the chemical nature of the substrate or the conditions selected for the interaction abound in the literature. ${ }^{6-8}$

In most cases, it is evident that electrostatic interactions play a fundamental role in the adsorption and can affect the conformation, structure, and bioactivity of adsorbed proteins. ${ }^{9,} 10$ Besides chemical modifications performed on the protein and/or the substrate, electrostatic interactions can be controlled in situ by the application of an external potential to the sorbent surface. A handful of reports have explored this possibility. Brusatori et al. ${ }^{11}$ showed that the rate of albumin adsorption was increased under an electric field while the rate of cytochrome $\mathrm{C}$ adsorption remained unchanged. Complementarily, it was demonstrated that the orientation, ${ }^{12}$ biocatalytic activity, ${ }^{13}$ and electron transfer kinetics $^{14,15}$ of cytochrome $\mathrm{C}$ can be also altered by the presence of an electric field. Bernabeu and Caprani ${ }^{16}$ found that the rate of adsorption and the area occupied by selected proteins (albumin and fibrinogen) can be affected by the surface charge on platinum and carbon electrodes. Later, Ying et al. ${ }^{2}$ reported that both positive and negative potentials promoted albumin adsorption to gold, probably due to the ability of the molecule to change its conformation on the surface. Moreover, Morrow et al. ${ }^{17}$ demonstrated that the adsorption of negatively-charged soybean peroxidase to gold can be controlled by an imposed electric field. Although the mechanism involved in this behavior was not described, they found that some proteins could be partially detached from the surface by applying a negative potential. Other properties of adsorbed peptides ${ }^{18}$ and proteins (such as insulin ${ }^{19}$ and green fluorescent protein $^{20}$ ) can be also modified by the presence of external potential. Although they highlight the potential advantages of affecting the adsorption process by the application of an external electric field to the adsorbent, most of these studies have been performed using metallic electrodes (that can form oxides upon the application of the electric field and offer narrow potential windows), electrically-asymmetric proteins (such as cytochrome $\mathrm{C}$ or insulin), or have not provided adequate electrochemical control (2-electrode setups). Addressing these shortcomings, this manuscript describes the effect of the external potential on the adsorption of bovine serum albumin (BSA) onto optically transparent carbon electrodes (OTCE). BSA was selected because it represents a model soft protein, which is prone to adsorption to a variety of surfaces under a wide range of experimental conditions. OTCE were selected as a sorbent surface because they are transparent, conductive, and feature a wide operational window without the formation of oxides. ${ }^{21,22}$ Adsorption experiments were performed under stagnation point flow conditions ${ }^{23}$ and followed (in real time) by spectroscopic ellipsometry as a function of potential applied, solution $\mathrm{pH}$, ionic strength, and protein concentration.

\section{Experimental Design}

\section{Reagents and Solutions}

All aqueous solutions were prepared using $18 \mathrm{M} \Omega \cdot \mathrm{cm}$ water (NANOpure Diamond, Barnstead; Dubuque, IA) and analytical-grade reagents. Citric acid was purchased from Aldrich Chemical Company (Milwaukee, WI). Brilliant Blue G was obtained from SigmaAldrich (St. Louis, MO). BSA, $\mathrm{NaOH}$, and anhydrous $\mathrm{NaH}_{2} \mathrm{PO}_{4}$ were purchased from Fisher Scientific (Fair Lawn, NJ). Citrate buffer was prepared by dissolving $1.9212 \mathrm{~g}$ of citric acid in ultrapure water to obtain $1 \mathrm{~L}$ of $10 \mathrm{mmol} \cdot \mathrm{L}^{-1}$ citric acid. To avoid changing its analytical concentration, the $\mathrm{pH}$ of the buffer was adjusted adding $1 \mathrm{~mol} \cdot \mathrm{L}^{-1} \mathrm{NaOH}$ dissolved in $10 \mathrm{mmol} \cdot \mathrm{L}^{-1}$ citrate solution and measured using a glass electrode and a digital pH meter (Orion 420A+, Thermo; Waltham, MA). Stock solutions of BSA (1.00, 0.50, 0.10, 0.05 and $0.01 \mathrm{mg} \cdot \mathrm{mL}^{-1}$ ) were prepared by dissolving a known amount of protein in a 10 $\mathrm{mmol} \cdot \mathrm{L}^{-1}$ buffer solution. 


\section{Substrates}

All experiments were performed using OTCE substrates, prepared following a previously described procedure. ${ }^{22}$ Details regarding the optical and electrochemical characterization of such films are also included in that publication. Briefly, a standard $\langle 111\rangle$ silicon wafer ( $\mathrm{Si} /$ $\mathrm{SiO}_{2}$, Sumco; Phoenix, AZ) was first scored using a computer-controlled engraver (Gravograph IS400, Gravotech; Duluth, GA), defining pieces of $1 \mathrm{~cm}$ in width and $3 \mathrm{~cm}$ in length that were then manually cut and cleaned in piranha solution (30\% hydrogen peroxide and $70 \%$ sulfuric acid) at $90{ }^{\circ} \mathrm{C}$ for $30 \mathrm{~min}$. After thorough rinsing with water, the substrates were immersed and stored in ultrapure water until use. Then, the wafers were coated with a layer of photoresist (AZ P4330-RS, AZ Electronic Materials; Somerville, NJ) using a spin coater (Laurell, WS-400-6NPP; North Wales, PA). In order to control the thickness of the OTCE, the photoresist was diluted to $60 \% \mathrm{v} / \mathrm{v}$ with propylene glycol monomethyl ether acetate (PGMEA 99\%, Alfa Aesar; Ward Hill, MA). Next, the photoresist-coated substrates were heated at $110^{\circ} \mathrm{C}$ for $60 \mathrm{~s}$ in a convection oven to evaporate the solvent and then transferred to a tube furnace (Thermolyne F21135, Barnstead International; Dubuque, IA) for pyrolysis. The carbonization step began by flushing the system at $1 \mathrm{~L} \cdot \mathrm{min}^{-1}$ with forming gas $\left(95 \% \mathrm{Ar}+5 \% \mathrm{H}_{2}\right.$, v/v) for $5 \mathrm{~min}$. Next, the temperature was increased to 1000 ${ }^{\circ} \mathrm{C}$ using a $20^{\circ} \mathrm{C} \cdot \mathrm{min}^{-1} \mathrm{ramp}$. After $1 \mathrm{~h}$, the system was allowed to cool down to room temperature in the presence of the forming gas. Finally, the samples were stored in a Petri dish for a minimum of 3 days to complete the spontaneous surface oxidation.

\section{Spectroscopic Ellipsometry}

Adsorption experiments were performed using a variable angle spectroscopic ellipsometer (WVASE, J.A. Woollam Co.; Lincoln, NE) following a procedure described elsewhere. ${ }^{23,} 24$ Spectroscopic Ellipsometry (SE) has proven suitable to study adsorption of proteins in real time and provides useful information about the thickness, optical constants, and structure of the adsorbed film. More information regarding the principle of SE can be found elsewhere. ${ }^{25}$ The mean square error (MSE, calculated by a built-in function in WVASE) was used to quantify the difference between the experimental and model-generated data. In agreement with previous reports, ${ }^{23,}{ }^{24}$ MSE $<15$ were considered acceptable.

Dynamic adsorption experiments were performed in a modified electrochemical cell ${ }^{23}$ (J.A. Woollam Co.; Lincoln, NE) mounted directly on the vertical base of the ellipsometer, with an incident angle of $70^{\circ}$. Before the BSA adsorption experiments, the thickness of the thin optically transparent carbon film was measured by placing the substrate in the ellipsometry cell and performing a spectroscopic scan from 300 to $1000 \mathrm{~nm}$ (with $10 \mathrm{~nm}$ steps) using 10 $\mathrm{mmol} \cdot \mathrm{L}^{-1}$ buffer solution as the ambient medium. Unless otherwise stated, a layer of protein was first adsorbed at open circuit potential (OCP, the potential at which no current flows through the cell) as follows. The dynamic experiment was started by pumping buffer to the surface of the OTCE at a rate of $1 \mathrm{~mL} \cdot \mathrm{min}^{-1}$ to establish the baseline. After $20 \mathrm{~min}$, the BSA solution was pumped to the surface and the adsorption began. An initial fast adsorption process, followed by a slower one, was always observed. After a plateau in the signal was observed, the selected potential $(+500,+650,+800$ or $+950 \mathrm{mV})$ was applied while the ellipsometric angles were monitored over time. As the two consecutive adsorption experiments were performed with the same protein, no washing steps were implemented. The applied potentials were selected taking into account the window potential of OTCE, which spans between $-0.4 \mathrm{~V}$ and $1.0 \mathrm{~V}$. The potential was applied using a CHI812B Electrochemical Analyzer (CH Instrument, Inc.; Austin, TX), a $\mathrm{Ag}|\mathrm{AgCl}| \mathrm{KCl}_{\text {sat }}$ reference electrode and a platinum wire as the counter electrode, mounted on the cell using ad hoc supports. This experimental procedure provided the data to calculate the thickness of the OTCE, the adsorbed amount of BSA, and the adsorption rate. In order to verify the thickness of the adsorbed layer of BSA, Brilliant Blue was added to the cell and the measurement 
repeated. ${ }^{26}$ This procedure changes the optical properties of the adsorbed protein layer, which can be represented using a simple optical model (Lorentz), increasing the sensitivity of the detection. The experimental data was used to determine the thickness $(d$, expressed in $\mathrm{nm})$ of the adsorbed layer. Then the adsorbed amount $\left(\Gamma\right.$, expressed in $\left.\mathrm{mg} \cdot \mathrm{m}^{-2}\right)$ was calculated using Equation 1,

$$
\Gamma=\frac{d\left(n-n_{0}\right)}{(d n / d c)} \quad \text { Equation } 1
$$

where $n$ and $n_{o}$ are the refractive index of the protein and of the ambient (aqueous buffer), respectively. In accordance with previous reports, ${ }^{24,} 27$ the refractive index increment for the proteins in the adsorbed layer $(d n / d c)$ was assumed to be $0.187 \mathrm{~mL} \cdot \mathrm{g}^{-1}$. BSA was considered as a model system to begin the study of protein adsorption to the substrates (OTCE). Thus, the physicochemical characteristics of this globular protein, such as molecular weight $(66.5 \mathrm{kDa}),{ }^{28}$ isoelectric point $(\mathrm{IEP}=4.7),{ }^{29}$ dimensions $(4 \mathrm{~nm} \times 4 \mathrm{~nm} \times$ $14 \mathrm{~nm}$ ), ${ }^{28}$ and glass transition temperature (defining it as a soft protein) ${ }^{3}$ were taken into account to analyze the experimental results.

\section{Atomic Force Microscopy (AFM)}

AFM was used to confirm the topography of the OTCE. Experiments were performed using a Veeco diMultimode Nanoscope V scanning probe microscope (Plainview, NY) operating in tapping and non-contact mode.

\section{Results}

\section{Development of the Optical Model}

The interpretation of ellipsometric measurements typically requires an optical model that describes the substrate microstructure in terms of the refractive index $(n)$, extinction coefficient $(k)$, and thickness $(d)$. Accordingly, a previously reported optical model ${ }^{21,22}$ was refined to include five uniaxial layers with optical axes parallel to the substrate surface (shown in Figure 1A).

In all cases, the ambient was represented using the optical properties of water. First, the silica wafer was described using the dielectric functions of $\mathrm{Si}$ (bulk, $\mathrm{d}=1 \mathrm{~mm})$ and $\mathrm{SiO}_{2}(d$ $=2.1 \pm 0.5 \mathrm{~nm})$. Then, the OTCE $(d=19.6 \pm 0.7 \mathrm{~nm})$ was described using the optical constants obtained experimentally in our lab and presented in a previous paper. ${ }^{22}$ In order to improve the accuracy of the model, it was necessary to incorporate a layer of void space representing nano-bubbles on the surface of the OTCE. In agreement with previous reports, ${ }^{30-33}$ the hydrophobic and rough surface of nanostructured materials (like the OTCE used in these experiments, see Figure 1B) can trap nano-sized bubbles in concave areas of the substrate that are retained on the surface due to unfavorable interactions with water. Finally, a Cauchy function was used to describe the layer of BSA. This arrangement allowed good agreement (MSE < 10) between the experimental and model-generated results. This model enabled the calculation of the thickness of the BSA layer, adsorbed onto the OTCE substrates.

\section{Effect of Potential on the Adsorption Process}

In order to investigate how the BSA adsorption is affected by the potential applied to the electrode surface, three distinct procedures were initially carried out. Representative results for the three modes are shown in Figure 2, where the adsorbed amount of BSA was calculated as a function of time. In the first case (Figure 2A, BSA adsorbed onto the OTCE 
at $\mathrm{OCP})$, it can be observed that the protein quickly adsorbs to the surface, reaching saturation $\left(1.5 \pm 0.2 \mathrm{mg} \cdot \mathrm{m}^{-2}\right)$ in less than $45 \mathrm{~min}$, under the selected experimental conditions. Considering the thickness calculated for this layer $(2.1 \pm 0.3 \mathrm{~nm})$, the dimensions of the protein, and the fact that BSA is a soft protein (prone to spreading $3,34,35$ ), these results suggest that BSA adopts a side-to-surface conformation under OCP conditions. In agreement with previous reports, $3,36,37$ this adsorption behavior has been attributed to a combination of hydrophobic and (to a lesser degree) electrostatic interactions between the surface and the protein as well as lateral interactions between protein molecules. As the surface coverage increases, the number of available sites decreases, therefore limiting the adsorption rate and leading to the plateau observed in Figure 2A.

It was also observed that if a potential is applied to the electrode surface (traces B and C in Figure 2), a significantly higher amount of BSA can be adsorbed to the OTCE. In addition, it was observed that the time at which the potential is applied to the electrode also has a significant impact on the adsorption process. If the potential is applied from the beginning of the experiment (Figure 2B), the adsorption process yields the formation of a thicker layer $\left(\sim 2.3 \mathrm{mg} \cdot \mathrm{m}^{-2}\right.$, at $\left.40 \mathrm{~min}\right)$ that continues to grow for as long as the potential is applied. As most experiments in the literature have been performed with charged proteins, this observation has been attributed to favorable electrostatic interactions between the surface and the protein. ${ }^{38,39}$ It is important to address that although this experimental design clearly supports the hypothesis that a potential applied to the electrode surface influences the adsorption process, it does not allow an independent evaluation of the effect of the applied potential during the initial stages of the interaction. In part, this limitation can be attributed to the high affinity of the protein for the surface that, even in the absence of the external potential, prevails over any other contribution and leads to the accumulation of protein on the surface. In order to separate these effects and perform a kinetic evaluation of the interaction upon the application of the potential to the electrode, experiments described in this manuscript were performed using OTCE substrates that were first modified with a layer of BSA, adsorbed under open circuit potential and using experimental conditions leading to fast saturation of the surface $\left(10 \mathrm{mmol} \cdot \mathrm{L}^{-1}\right.$ citrate, $\mathrm{pH}=4.7$, and $\left.0.50 \mathrm{mg} \cdot \mathrm{L}^{-1} \mathrm{BSA}\right)$. This set-up also minimized the effect of slight differences (thickness and/or surface properties) between OTCE prepared in different batches. As can be observed in Figure $2 \mathrm{C}$, the thickness (and the adsorbed amount) of the protein layer increased upon the application of the external potential. The adsorption rate upon the application of the potential $\left(\mathrm{d} \Gamma / \mathrm{dt}_{1}\right)$, calculated from the $\Gamma$-t plot in the first seconds of the experiment was $0.014 \pm 0.002$ $\mathrm{mg} \cdot \mathrm{m}^{-2} \cdot \mathrm{min}^{-1}$. This value is substantially lower than the adsorption rate of BSA to the bare surface of the OTCE with or without the application of external potential $(2.0 \pm 0.3$ $\left.\mathrm{mg} \cdot \mathrm{m}^{-2} \cdot \mathrm{min}^{-1}\right)$.

It was observed that applying a potential to the electrode surface can lead to higher amounts of protein adsorbed to the surface. For example, in a case where the adsorption process was followed for $\sim 15$ hours during the application of $+800 \mathrm{mV}$ (see Supplementary Information), a steady increase in the adsorbed amount was observed, reaching almost 8 times the amount obtained at OCP $\left(17.6 \pm 0.8 \mathrm{mg} \cdot \mathrm{m}^{-2}\right)$. These findings not only are the highest adsorbed amounts reported in literature to date, but also indicate that the effect of the applied potential is able to propagate through the layer of adsorbed BSA. Furthermore, the results shown in Figure 2 indicate that multiple layers of protein can accumulate on to (conductive) solid surfaces. The time constants for such processes are significantly slower (on the order of $10^{-3}$ ) than those associated with the formation of the first layer of protein onto the bare OTCE surface. Since the presented results were verified by the addition of Brilliant Blue (yielding to a signal that is proportional to the amount of protein adsorbed), the observed changes cannot be attributed to the protrusion of the protein layer towards the solution (which could increase the thickness of the layer with constant amount of protein). ${ }^{3,5,40}$ 
Other effects such as the roughness of the substrate ${ }^{41}$ or the so-called electro-optic effect ${ }^{42}$ have been discarded in control experiments.

\section{Effect of the Magnitude of the Applied Potential}

The adsorption of BSA was also investigated as a function of the magnitude of the potential applied. In all cases, the adsorption experiment began by recording the baseline (bare electrode) and then allowing a monolayer of BSA to adsorb on the surface of the OTCE at OCP $(2.1 \pm 0.3 \mathrm{~nm})$. After $60 \mathrm{~min}$, when stable readings were obtained for the ellipsometric angles, the selected potential was applied and maintained until the end of the experiment. In order to favor electrostatic interactions between BSA and the surface (anodically polarized), experiments were performed at $\mathrm{pH}=5.7$ (above IEP). Representative results are shown in Figure 3.

As can be observed, when $+500 \mathrm{mV}$ was applied to the OTCE, no significant differences in the thickness of the layer (and the adsorbed amount) were observed. The same behavior was also observed when potential values in the $-500 \mathrm{mV} /+500 \mathrm{mV}$ range were applied (data not shown). Higher potential values, however, induced the accumulation of BSA molecules, leading to significant changes in the thickness of the layer (and the adsorbed amount). In all cases, a fast growth in the protein layer was observed within the first $15 \mathrm{sec}$ upon the application of the potential $\left(\mathrm{d} \Gamma / \mathrm{dt}_{1}\right)$, followed by a slower process $\left(\mathrm{d} \Gamma / \mathrm{dt}_{2}\right)$ that remained constant until the end of the experiment. Table 1 summarizes the results calculated (using the least square method) for each of those processes as a function of the potential applied to the electrode surface.

The observed increases in the adsorbed amount have been attributed to the polarization of the adsorbed layer and the subsequent electrostatic interaction with the incoming protein molecules. Likely, the inherent flexibility of BSA plays a critical role in the described effect, making its tertiary structure particularly susceptible to structural changes as a response to electrical conditions. Several papers have described the possibility of inducing changes in the adsorbed layer based on redox processes involving the adsorbed protein. It is also important to note that many of these reports are based on the immobilization redox-active proteins (such as ferredoxin ${ }^{43}$ ) or the adsorption of proteins to electro-active susbtrates (for example mercury amalgams, ${ }^{9} \mathrm{PoPD} / \mathrm{C}-\mathrm{Ni} / \mathrm{GCE},{ }^{44}$ or doped polypyrrole ${ }^{45}$ ). In limited cases, BSA shows an oxidation peak at potential values in the $700 \mathrm{mV}^{46,47}$ to $800 \mathrm{mV}^{48,49}$ range, which have been attributed to the oxidation of three amino acids (cysteine, tryptophan and tyrosine) that, after protein adsorption, are in close proximity to the electrode surface. In order to verify that redox processes are not associated with the changes described in the manuscript, cyclic voltammetry was performed before and after the protein was adsorbed to the electrode. While it was observed that the adsorption of BSA onto OTCE induced increases in the capacitance of the substrate, no evident redox peaks were obtained within the selected potential window (see Supplementary Information). Therefore, in order to induce fast changes in the adsorbed layer while minimizing the possibility of inducing redox processes in the adsorbed layer, $+800 \mathrm{mV}$ was considered optimal and used for the remaining experiments.

\section{Effect of the pH}

Among other alternatives to manipulate the charge of proteins, ${ }^{50,51}$ adjusting the $\mathrm{pH}$ of the solution is probably the simplest one. Therefore, adsorption experiments were performed in BSA solutions buffered in the 3.7 - 6.7 range. This range was selected to include the IEP of BSA $\left(4.7^{29}, 52\right)$ while retaining sufficient buffer capacity in the ambient solution (citrate $\left.\mathrm{pKa}_{1}=3.14, \mathrm{pKa}_{2}=4.77, \mathrm{pKa}_{3}=6.39\right) .{ }^{53}$ In order to gain preliminary insights about the effect of electrode potential on the adsorption of BSA under physiological conditions, 
additional experiments performed at $\mathrm{pH}=7.2$ (buffered with $10 \mathrm{mmol} \cdot \mathrm{L}^{-1}$ phosphate) were also performed. Under these conditions, the zeta potential of BSA spans $\pm 15 \mathrm{mV}^{54}$ and could lead to conformational changes in the protein, ${ }^{29,55}$ and varied surface coverage, depending on the $\mathrm{pH}^{52,56-58}$ Therefore, to minimize variability in the thickness of the BSA/ OTCE substrate used for the experiments, the first layer of BSA was adsorbed to the OTCE at $\mathrm{pH}=4.7$, yielding a monolayer of protein with an average thickness of $3.5 \pm 0.7 \mathrm{~nm}$ (after $40 \mathrm{~min}$ at $\mathrm{OCP}$ ). Then, the solution impinging the substrate was sequentially replaced by the buffer at the selected $\mathrm{pH}$ value and then by a solution containing BSA (prepared in the selected buffer) to establish the baseline (at OCP and the $\mathrm{pH}$ selected for the experiment). No spontaneous adsorption of BSA was observed within the $\mathrm{pH}$ range studied. Next, the potential $(+800 \mathrm{mV})$ was applied to the electrode surface and the adsorption process followed by SE. In all cases, the two previously described processes were observed after the potential was applied, leading to the accumulation of BSA on the substrate. As a summary, Figure 4 shows the relative increase in thickness of the BSA layer after 3 hours, defining $100 \%$ as the thickness of the first layer of BSA adsorbed to the OTCE.

As seen in Figure 4, a significant increase in the thickness (and adsorbed amount) of the BSA layer was observed upon the application of the external potential at all studied $\mathrm{pH}$ values. As these changes correspond to the change in thickness upon the application of the potential, they cannot be attributed to differences in conformation of BSA. ${ }^{29}$ The increase in thickness (and absorbed amount) obtained above the IEP has traditionally been explained by considering the electrostatic attraction between the positively charged surface and the negatively charged protein; however the large increases obtained below the IEP (electrode polarized at $+800 \mathrm{mV}$, positively charged protein) contrast with the expected electrostatic behavior. Furthermore, the largest change in adsorbed amount was obtained at the IEP, yielding a 2.5-fold increase in the thickness of the resulting layer. These findings suggest that electrostatic interactions between the sorbent surface and the protein being adsorbed (while possibly present) are much less relevant than other processes induced by the external electric field.

\section{Effect of BSA Concentration}

The effect of BSA concentration was evaluated in the $0.01-1.00 \mathrm{mg} \cdot \mathrm{mL}^{-1}$ range. Again, the experiment was performed by first adsorbing a monolayer of BSA $\left(10 \mathrm{mmol} \cdot \mathrm{L}^{-1}\right.$ citrate, $\mathrm{pH}$ $=4.7,40 \mathrm{~min})$ on the OTCE at OCP. Next, the impinging solution $\left(10 \mathrm{mmol} \cdot \mathrm{L}^{-1}\right.$ citrate, $\mathrm{pH}$ $=4.7$, containing BSA at the selected concentration) was pumped to the cell for 20 min to evaluate the stability of adsorbed protein layer and to establish a baseline. Then, the potential was applied and the experiment followed for additional $220 \mathrm{~min}$. Figure 5 shows representative results related to the dynamic adsorption of BSA in the conditions above described.

As shown in the figure, no desorption was observed after rinsing the surface with either the citrate buffer solution or any of the BSA solutions introduced in the cell. A change in the thickness (and adsorbed amount) of the BSA layer was only observed when the potential was applied to the sorbent surface. The kinetics of the adsorption process $\left(\mathrm{d} \Gamma / \mathrm{dt}_{1}\right.$ and $\mathrm{d} \Gamma /$ $\mathrm{dt}_{2}$ ) were found to be proportional to the concentration of BSA used in each experiment. These results indicate that the attachment of BSA is controlled by the number of protein molecules arriving to the sorbent surface. However, by comparing the adsorption rate obtained at the bare OTCE $\left(2.0 \pm 0.3 \mathrm{mg} \cdot \mathrm{m}^{-2} \cdot \mathrm{min}^{-1}\right)$ and the adsorption rate obtained upon the application of the potential $\left(1.75 \pm 0.01 \times 10^{-3} \mathrm{mg} \cdot \mathrm{m}^{-2} \cdot \mathrm{min}^{-1}\right) \mathrm{using} 0.10 \mathrm{mg} \cdot \mathrm{mL}^{-1}$ $\mathrm{BSA}$, it is evident that only a small fraction of the incoming protein molecules can be adsorbed in the latter case. 


\section{Effect of lonic Strength}

In order to investigate the contribution of electrostatic interactions on the adsorption process assisted by potential, the effect of ionic strength was investigated. For these experiments, a monolayer of BSA was first adsorbed $\left(10 \mathrm{mmol} \cdot \mathrm{L}^{-1}\right.$ citrate, $\mathrm{pH}=4.7,0.50 \mathrm{mg} \cdot \mathrm{mL}^{-1} \mathrm{BSA}$, $40 \mathrm{~min}$ ) on the OTCE at OCP. Next, the impinging solution was switched to a solution containing the selected concentration of $\mathrm{NaCl}$ (prepared in $10 \mathrm{mmol} \cdot \mathrm{L}^{-1}$ citrate buffer at $\mathrm{pH}$ $=4.7,0.50 \mathrm{mg} \cdot \mathrm{mL}^{-1} \mathrm{BSA}$ ) for $20 \mathrm{~min}$. Finally, the potential was changed from OCP to $+800 \mathrm{mV}$ to induce accumulation on the surface. The results are summarized in Figure 6 . After the BSA/OTCE substrate was exposed to increasing concentrations of $\mathrm{NaCl}$ (between 60 and $80 \mathrm{~min}$ ), a slight decrease in the thickness of the adsorbed layer was observed. Rather than desorption of BSA from the substrate, this decrease can be attributed to a compression of the protein layer due to shielding of the electrostatic interaction within the adsorbed protein molecules and was not considered significant.

Upon the application of the potential, substantial increases in the thickness (and adsorbed amount) were observed. The kinetics of the adsorption process $\left(\mathrm{d} \Gamma / \mathrm{dt}_{1}\right.$ and $\left.\mathrm{d} \Gamma / \mathrm{dt}_{2}\right)$ were found to be inversely proportional to the concentration of $\mathrm{NaCl}$ used in each experiment. These results (performed at the IEP of the protein) indicate that the potential applied to the substrate is able to affect the adsorption process and that the ions present in the surrounding solution are able to reduce that interaction. The observed effect is opposite to the behavior observed when the adsorption experiment is performed with charged proteins, ${ }^{40,59,60}$ where increasing concentrations of ions can increase the adsorbed amount by either complexation with oppositely charged patches or electrostatic shielding.

\section{Summary and Discussion}

The experiments described in this manuscript have used the surface of an optically transparent carbon electrode saturated with a layer of BSA (as the sorbent substrate) to investigate the effect of an external potential applied on the adsorption of subsequent BSA molecules. Only potential values higher than $+500 \mathrm{mV}$ (applied to the substrate), promoted the accumulation of BSA on the substrate. Both the magnitude of the resulting change (arbitrarily determined at $250 \mathrm{~min}$ ) and the kinetics of the process showed a significant dependence on the experimental conditions selected. In general, application of higher potentials, selection of $\mathrm{pH}$ values around the IEP of the protein, high concentrations of protein, and low ionic strengths yielded faster kinetics and the accumulation of larger amounts of BSA on the substrate. The obtained values are compatible with the formation of a disordered system composed of multiple layers of protein.

In a traditional adsorption experiment (performed at $\mathrm{OCP}$ ), these findings would suggest that the adsorption process is driven by a gain in entropy and the formation of attractive noncovalent interactions such as van der Waals forces and hydrogen bonds of the BSA hydration shell, ${ }^{58}$ overpowering lateral electrostatic repulsions, when relevant. At OCP also, BSA molecules could also form an arrangement favoring electrostatic interactions between negative and positive patches in the protein (polar ordering ${ }^{58}$ ) or enclose counterions leading to the formation of a multilayer system. However, the described accumulation of BSA on the substrate (OTCE/BSA) was only observed when the potential was applied. Although similar experiments have been previously described, the results obtained around the IEP of the protein are in contrast with the accepted hypothesis that enhanced electrostatic interactions between the polarized substrate and the (oppositely charged) protein are solely responsible for the enhanced adsorption.

To explain these results, it is necessary to consider that the rate of adsorption at the solid/ liquid interface can be generally described by the transport of the solute molecules from the 
bulk to the interface, the attachment to the surface, and the relaxation on the surface. When the concentration at the surface is zero, the flux of adsorbate $(\mathrm{J})$ towards the surface can be described by Equation 2,

$$
J=0.776 v^{1 / 3} R^{-1}(\alpha \operatorname{Re})^{1 / 3} D^{2 / 3} \beta \gamma C \quad \text { Equation } 2
$$

where $v$ is the kinematic viscosity of the solvent, $\mathrm{R}$ is the inner radius of the tube through which the solution enters the cell, $D$ is the diffusion coefficient of the studied adsorbate, $\beta$ is the probability of attachment, $\gamma$ is a correction factor that accounts for the geometry of the cell, ${ }^{23}$ and $C$ is the concentration of the adsorbate in the bulk. Around the isoelectric point, the probability of attachment of BSA to the bare surface of the OTCE can be approximated to be one, leading to $\mathrm{d} \Gamma / \mathrm{dt}_{0}$ values that increase linearly with the concentration of BSA in solution, until a plateau is reached at approximately $0.1 \mathrm{mg} \cdot \mathrm{mL}^{-1}$.

Therefore, it is reasonable to assume that in the experiments designed to investigate the effect of the potential applied to the electrode, there is enough BSA supplied to the surface to sustain a much higher adsorption rate than the observed. However, the probability of attachment of BSA to the BSA/OTCE surface is much lower than the probability of attachment to the bare OTCE surface. According to the described results, the potential applied to the electrode is able to increase this probability, allowing other proteins to adsorb and grow the layer. The hypothesis is that this phenomenon can be associated to the possibility of polarizing the incoming adsorbing molecules. As schematically shown in Figure 7, when the experiment is performed at OCP, BSA is able to form a rather compact layer of protein adsorbed to the electrode surface.

As no desorption was observed and thickness values lower than the dimensions of the protein were obtained, it is reasonable to assume that after the interaction with the surface, BSA underwent structural rearrangements (spreading). At this point, and although more protein can reach the substrate, the absence of available sites limits the adsorption and the surface is considered to be saturated.

On the other side, if a potential (larger than $+500 \mathrm{mV}$ vs $\mathrm{Ag}|\mathrm{AgCl}| \mathrm{KCl}_{\mathrm{sat}}$ ) is then applied, the surface of the electrode (OTCE/BSA) becomes polarized. The larger the applied potential, the larger the effect. More importantly, comparing the adsorption rates it can be concluded that the probability for incoming proteins to get close enough to the surface, become polarized, and adsorb to the substrate is about 1 in 1000. Because a rather constant adsorption rate was observed (within the time course described in this manuscript), the polarization effect does not seem to be limited by the thickness of the layer.

Because BSA is a "soft" protein, it is probably particularly prone to this polarization effect that can be attributed to the alignment of individual dipoles present in the protein (charged amino acids, peptidic bonds, etc.). The experiments performed as a function of solution $\mathrm{pH}$ suggest that this effect is more pronounced at the isoelectric point of the protein. The experiments performed as a function of the concentration of protein indicate that as more protein molecules impinge on the surface, more proteins can become polarized molecules, increasing the adsorption rate. Moreover, this hypothesis is also in agreement with the experiments performed at different ionic strengths, which showed that increasing amounts of salt decreased the adsorption rate. We believe that this observation can be attributed to the shielding effect exerted by the ions in solution, which can shield the incoming proteins from the electric field applied to the surface. Also in agreement with the soft nature of BSA, it is important to note that no significant desorption of BSA was observed, enabling the gentle rinse of the surface without affecting the thickness of the adsorbed layer. 


\section{Conclusions}

The adsorption of BSA onto OTCE was investigated using spectroscopic ellipsometry, coupled to chronoamperometry and under different experimental conditions $(\mathrm{pH}$, protein concentration, and ionic strength). The experimental results suggest that the potential applied at the BSA/OTCE interface can polarize the substrate and induce the polarization of a fraction of the BSA molecules present in the proximity of the surface. This polarization effect could result in a new route to promote the immobilization of larger amounts of macromolecules to solid surfaces, leading to the development of surfaces with unparalleled biological properties and catalytic activity.

\section{Supplementary Material}

Refer to Web version on PubMed Central for supplementary material.

\section{Acknowledgments}

Financial support for this project has been provided in part by the University of Texas at San Antonio and the National Institutes of Health through the National Institute of General Medical Sciences (2SC3GM081085) and the Research Centers at Minority Institutions (G12MD007591).

\section{References}

1. Norde, W. Proteins at Solid Surfaces. Physical Chenistry of Biological Interfaces. Marcel Dekker; New York: 2000.

2. Ying P, Viana AS, Abrantes LM, Jin G. Adsorption of human serum albumin onto gold: a combined electrochemical and ellipsometric study. J Colloid Interface Sci. 2004; 279(1):95-99. [PubMed: 15380416]

3. Norde W, Giacomelli CE. BSA structural changes during homomolecular exchange between the adsorbed and the dissolved states. J Biotechnol. 2000; 79(3):259-268. [PubMed: 10867186]

4. Vermeer AWP, Norde W. CD Spectroscopy of Proteins Adsorbed at Flat Hydrophilic Quartz and Hydrophobic Teflon Surfaces. J Colloid Interface Sci. 2000; 225(2):394-397. [PubMed: 11254277]

5. Norde W. My voyage of discovery to proteins in flatland ... and beyond. Colloids Surf B. 2008; 61(1):1-9.

6. Zhang L, Sun Y. Molecular simulation of adsorption and its implications to protein chromatography: A review. Biochem Eng J. 2010; 48(3):408-415.

7. Rabe M, Verdes D, Seeger S. Understanding protein adsorption phenomena at solid surfaces. Adv Colloid Interface Sci. 2011; 162(1-2):87-106. [PubMed: 21295764]

8. Vogler EA. Protein adsorption in three dimensions. Biomaterials. 2012; 33(5):1201-1237. [PubMed: 22088888]

9. Palecek E, Ostatna V. Ionic strength-dependent structural transition of proteins at electrode surfaces. Chem Comm. 2009; (13):1685-1687. [PubMed: 19294262]

10. Palecek E, Ostatna V. Potential-dependent surface denaturation of BSA in acid media. Analyst. 2009; 134(10):2076-2080. [PubMed: 19768216]

11. Brusatori MA, Tie Y, Van Tassel PR. Protein Adsorption Kinetics under an Applied Electric Field: An Optical Waveguide Lightmode Spectroscopy Study. Langmuir. 2003; 19(12):5089-5097.

12. Fraaije JG, Kleijn JM, van der Graaf M, Dijt JC. Orientation of adsorbed cytochrome c as a function of the electrical potential of the interface studied by total internal reflection fluorescence. Biophys J. 1990; 57(5):965-975. [PubMed: 2160300]

13. Song YY, Li Y, Yang C, Xia XH. Surface electric field manipulation of the adsorption kinetics and biocatalytic properties of cytochrome $\mathrm{c}$ on a 3D macroporous Au electrode. Anal Bioanal Chem. 2008; 390(1):333-341. [PubMed: 17955215] 
14. Kranich A, Ly HK, Hildebrandt P, Murgida DH. Direct Observation of the Gating Step in Protein Electron Transfer: Electric-Field-Controlled Protein Dynamics. J Am Chem Soc. 2008; 130(30): 9844-9848. [PubMed: 18593159]

15. De Biase PM, Paggi DnA, Doctorovich F, Hildebrandt P, Estrin DA, Murgida DH, Marti MA. Molecular Basis for the Electric Field Modulation of Cytochrome c Structure and Function. J Am Chem Soc. 2009; 131(44):16248-16256. [PubMed: 19886701]

16. Bernabeu P, Caprani A. Influence of surface charge on adsorption of fibrinogen and/or albumin on a rotating disc electrode of platinum and carbon. Biomaterials. 1990; 11(4):258-264. [PubMed: 2383621]

17. Morrow R, McKenzie DR, Bilek MMM, MacDonald CL, Stindt M, Anetsberger G, Martin AS. Electric field effects on adsorption/desorption of proteins and colloidal particles on a gold film observed using surface plasmon resonance. Physica B. 2007; 394(2):203-207.

18. Toschi F, Lugli F, Biscarini F, Zerbetto F. Effects of Electric Field Stress on a $\beta$-Amyloid Peptide. J Phys Chem B. 2008; 113(1):369-376. [PubMed: 19063666]

19. Budi A, Legge FS, Treutlein H, Yarovsky I. Electric Field Effects on Insulin Chain-B Conformation. J Phys Chem B. 2005; 109(47):22641-22648. [PubMed: 16853947]

20. Nakabayashi T, Kinjo M, Ohta N. Electric field effects on fluorescence of the green fluorescent protein. Chem Phys Lett. 2008; 457(4-6):408-412.

21. Alharthi SA, Benavidez TE, Garcia CD. Ultrathin Optically Transparent Carbon Electrodes Produced from Layers of Adsorbed Proteins. Langmuir. 2013; 29(10):3320-3327. [PubMed: 23421732]

22. Benavidez TE, Garcia CD. Spectroscopic and electrochemical characterization of nanostructured optically transparent carbon electrodes. Electrophoresis. 2013:n/a-n/a.

23. Mora MF, Reza Nejadnik M, Baylon-Cardiel JL, Giacomelli CE, Garcia CD. Determination of a setup correction function to obtain adsorption kinetic data at stagnation point flow conditions. J Colloid Interface Sci. 2010; 346(1):208-215. [PubMed: 20219204]

24. Nejadnik MR, Francis L, Garcia CD. Nanoscale Scaffolds of Carbon Nanotubes for Immobilization of Glucose Oxidase. Electroanalysis. 2011; 23(6):1462-1469. [PubMed: 22735356]

25. Fujiwara, H. Principles and applications. J. Wiley \& Sons; West Sussex, England: 2007. Spectroscopic ellipsometry.

26. Nejadnik MR, Garcia CD. Staining proteins: A simple method to increase the sensitivity of ellipsometric measurements in adsorption studies. Colloids Surf B. 2011; 82(1):253-257.

27. Wen J, Arakawa T. Refractive Index of Proteins in Aqueous Sodium Chloride. Anal Biochem. 2000; 280(2):327-329. [PubMed: 10790320]

28. Squire PG, Moser P, O'Konski CT. Hydrodynamic properties of bovine serum albumin monomer and dimer. Biochem. 1968; 7(12):4261-4272. [PubMed: 5750167]

29. Carter DC, Ho JX. Structure of serum albumin. Adv Protein Chem. 1994; 45:153-203. [PubMed: 8154369]

30. Hampton MA, Nguyen AV. Nanobubbles and the nanobubble bridging capillary force. Adv Colloid Interface Sci. 2010; 154(1-2):30-55. [PubMed: 20152956]

31. Tyrrell JWG, Attard P. Images of Nanobubbles on Hydrophobic Surfaces and Their Interactions. Phys Rev Lett. 2001; 87(17):176104. [PubMed: 11690285]

32. Borkent BM, Dammer SM, Schönherr H, Vancso GJ, Lohse D. Superstability of Surface Nanobubbles. Phys Rev Lett. 2007; 98(20):204502. [PubMed: 17677702]

33. Craig VSJ. Very small bubbles at surfaces-the nanobubble puzzle. Soft Matter. 2011; 7(1):40-48.

34. Giacomelli CE, Norde W. The Adsorption-Desorption Cycle. Reversibility of the BSA-Silica System. J Colloid Interface Sci. 2001; 233(2):234-240. [PubMed: 11121271]

35. van der Veen M, Stuart MC, Norde W. Spreading of proteins and its effect on adsorption and desorption kinetics. Colloids Surf B. 2007; 54(2):136-142.

36. Morrin A, Guzman A, Killard AJ, Pingarrón JM, Smyth MR. Characterisation of horseradish peroxidase immobilisation on an electrochemical biosensor by colorimetric and amperometric techniques. Biosens Bioelectron. 2003; 18(5-6):715-720. [PubMed: 12706583] 
37. Edri E, Regev O. pH Effects On BSA-Dispersed Carbon Nanotubes Studied by SpectroscopyEnhanced Composition Evaluation Techniques. Anal Chem. 2008; 80(11):4049-4054. [PubMed: 18459735]

38. Xie Y, Liao C, Zhou J. Effects of external electric fields on lysozyme adsorption by molecular dynamics simulations. Biophys Chem. 2013; 179(0):26-34. [PubMed: 23727988]

39. Koutsioubas A, Lairez D, Zalczer G, Cousin F. Slow and remanent electric polarization of adsorbed BSA layer evidenced by neutron reflection. Soft Matter. 2012; 8(9):2638-2643.

40. Norde, W. Driving Forces for Protein Adsorption at Solid Surfaces. In: Malmsten, M., editor. Biopolymers at Interfaces. Marcel Dekker; New York: 2003. p. 110

41. Dolatshahi-Pirouz A, Rechendorff K, Hovgaard MB, Foss M, Chevallier J, Besenbacher F. Bovine serum albumin adsorption on nano-rough platinum surfaces studied by QCM-D. Colloids Surf B. 2008; 66(1):53-59.

42. Abbas Z, Christian F, Thomas Garm P. Theoretical study of quadratic electro-optic effect in semiconducting zigzag carbon nanotubes. Phys Rev B. 2007; 76(4):045403.

43. Armstrong FA, Hill HAO, Walton NJ. Direct electrochemical oxidation of Clostridium pasteurianum ferredoxin: Identification of facile electron-transfer processes relevant to cluster degradation. FEBS Letters. 1982; 150(1):214-218.

44. Bian C, Xiong H, Zhang X, Wen W, Wang S. An electrochemical biosensor for analysis of Fentonmediated oxidative damage to BSA using poly-o-phenylenediamine as electroactive probe. Biosens Bioelectron. 2011; 28(1):216-220. [PubMed: 21816601]

45. Molino PJ, Higgins MJ, Innis PC, Kapsa RMI, Wallace GG. Fibronectin and Bovine Serum Albumin Adsorption and Conformational Dynamics on Inherently Conducting Polymers: A QCMD Study. Langmuir. 2012; 28(22):8433-8445. [PubMed: 22551342]

46. Chiku M, Ivandini TA, Kamiya A, Fujishima A, Einaga Y. Direct electrochemical oxidation of proteins at conductive diamond electrodes. J Electroanal Chem. 2008; 612(2):201-207.

47. Chiku M, Nakamura J, Fujishima A, Einaga Y. Conformational Change Detection in Nonmetal Proteins by Direct Electrochemical Oxidation Using Diamond Electrodes. Anal Chem. 2008; 80(15):5783-5787. [PubMed: 18613649]

48. Vacek J, Vrba J, Zatloukalová M, Kubala M. Electrochemical oxidation of proteins using ionic liquids as solubilizers, adsorption solvents and electrolytes. Electrochim Acta.

49. Wei MY, Famouri P, Guo LH. Electrocatalytic oxidation of tyrosines shows signal enhancement in label-free protein biosensors. TrAC, Trends Anal Chem. 2012; 39(0):130-148.

50. Gao Y, Kyratzis I. Covalent Immobilization of Proteins on Carbon Nanotubes Using the CrossLinker 1-Ethyl-3-(3-dimethylaminopropyl)carbodiimideâ "a Critical Assessment. Bioconjugate Chem. 2008; 19(10):1945-1950.

51. Hermanson, GT. Bioconjugate Techniques. 2. Academic Press Inc; 2008.

52. Chumbimuni-Torres KY, Coronado RE, Mfuh AM, Castro-Guerrero C, Silva MF, Negrete GR, Bizios R, Garcia CD. Adsorption of Proteins to Thin-Films of PDMS and Its Effect on the Adhesion of Human Endothelial Cells. RSC Advances. 2011; (4):706-714.

53. Lide, DR. CRC Handbook of Chemistry and Physics. 77. CRC Press; 1996. 1996-1997

54. Salis A, Bostroým M, Medda L, Cugia F, Barse B, Parsons DF, Ninham BW, Monduzzi M. Measurements and Theoretical Interpretation of Points of Zero Charge/Potential of BSA Protein. Langmuir. 2011; 27(18):11597-11604. [PubMed: 21834579]

55. Ferrer ML, Duchowicz R, Carrasco B, de la Torre JG, Acuña AU. The Conformation of Serum Albumin in Solution: A Combined Phosphorescence Depolarization-Hydrodynamic Modeling Study. Biophys J. 2001; 80(5):2422-2430. [PubMed: 11325741]

56. Valenti LE, Fiorito PA, Garcia CD, Giacomelli CE. The adsorption-desorption process of bovine serum albumin on carbon nanotubes. J Colloid Interface Sci. 2007; 307(2):349-356. [PubMed: 17174970]

57. Wehmeyer J, Bizios R, Garcia CD. Adsorption of Bovine Serum Albumin to Nanostructured ThinFilms of $\mathrm{TiO}_{2}$. Mat. Sci. Eng C. 2010; 30(2):277-282.

58. Engelhardt K, Rumpel A, Walter J, Dombrowski J, Kulozik U, Braunschweig B, Peukert W. Protein Adsorption at the Electrified Air-Water Interface: Implications on Foam Stability. Langmuir. 2012; 28(20):7780-7787. [PubMed: 22530646] 
59. van der Veen M, Norde W, Stuart MC. Electrostatic interactions in protein adsorption probed by comparing lysozyme and succinylated lysozyme. Colloids Surf B. 2004; 35(1):33-40.

60. de Vos WM, Biesheuvel PM, de Keizer A, Kleijn JM, Cohen Stuart MA. Adsorption of the Protein Bovine Serum Albumin in a Planar Poly(acrylic acid) Brush Layer As Measured by Optical Reflectometry. Langmuir. 2008; 24(13):6575-6584. [PubMed: 18507422] 
A)

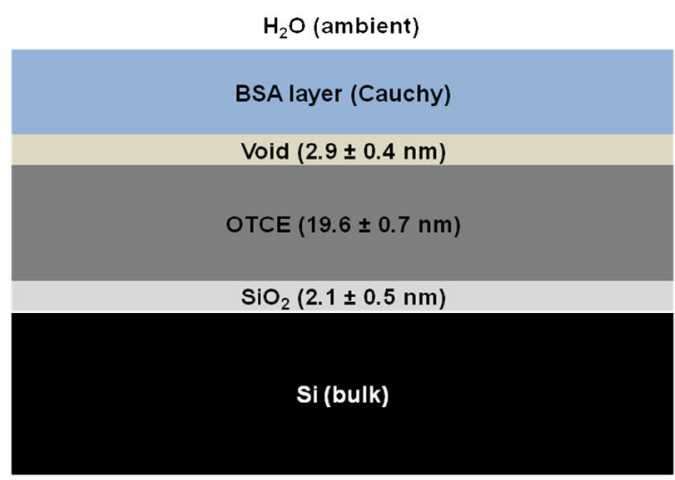

B)

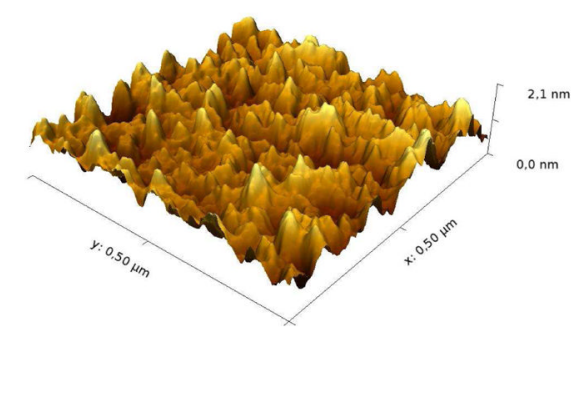

Figure 1.

A) Ellipsometric model used to interpret the optical behavior of adsorbed protein layer. B) AFM micrograph of the surface of the OTCE used as substrate for adsorption experiments of BSA. 


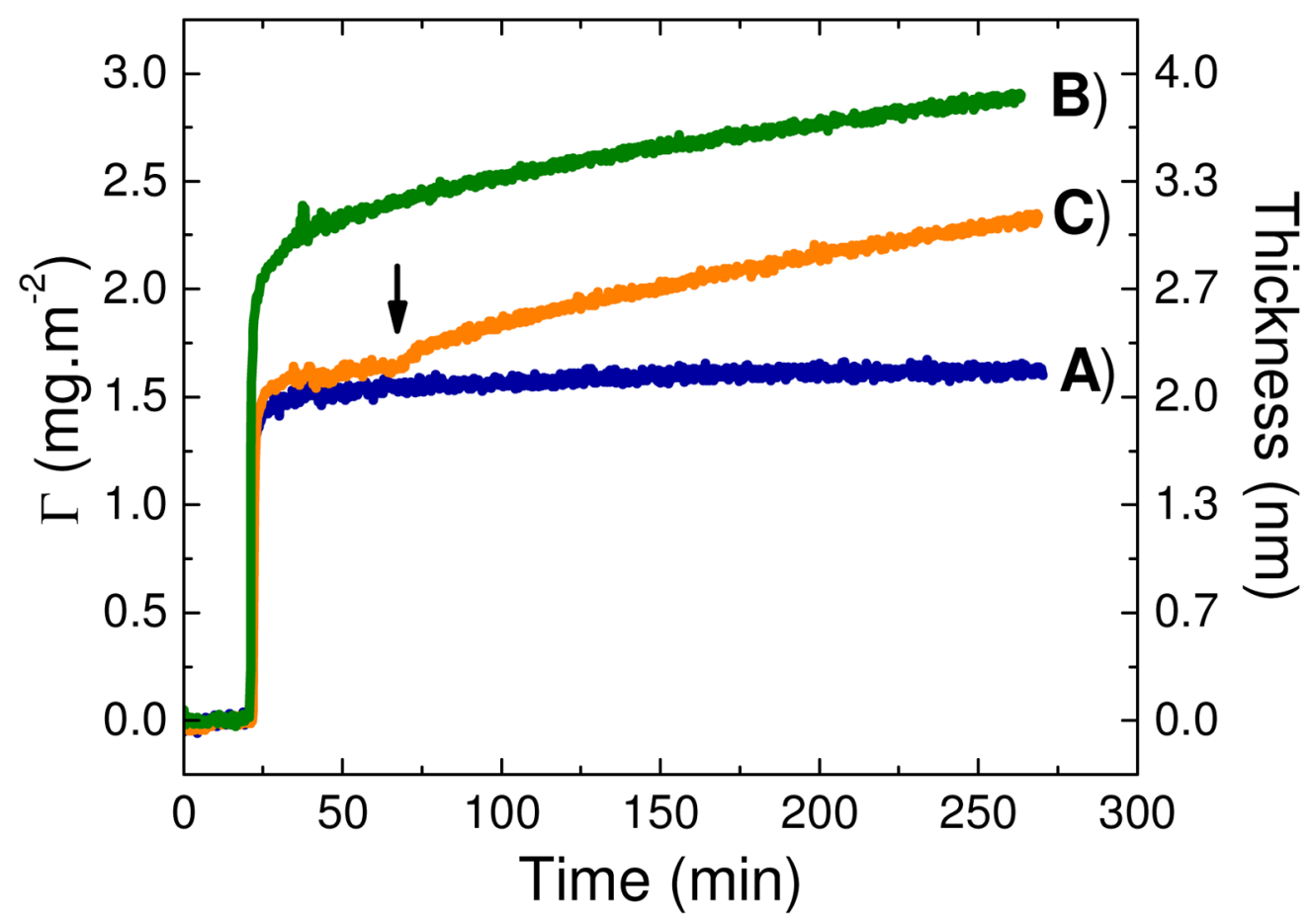

Figure 2.

Dynamic adsorption experiment of BSA onto OTCE at open circuit potential (A), when 800 $\mathrm{mV}$ were applied from $\mathrm{t}=0(\mathrm{~B})$; and when $+800 \mathrm{mV}$ from were applied at $\mathrm{t}=60$ (marked with the arrow). Conditions: $0.50 \mathrm{mg} \cdot \mathrm{mL}^{-1} \mathrm{BSA}, d_{\mathrm{OTCE}}=19.6 \pm 0.7 \mathrm{~nm}, 10 \mathrm{mmol} \cdot \mathrm{L}^{-1}$ citrate buffer at $\mathrm{pH}=5.7$, flow rate of $1 \mathrm{~mL} \cdot \mathrm{min}^{-1}$. 


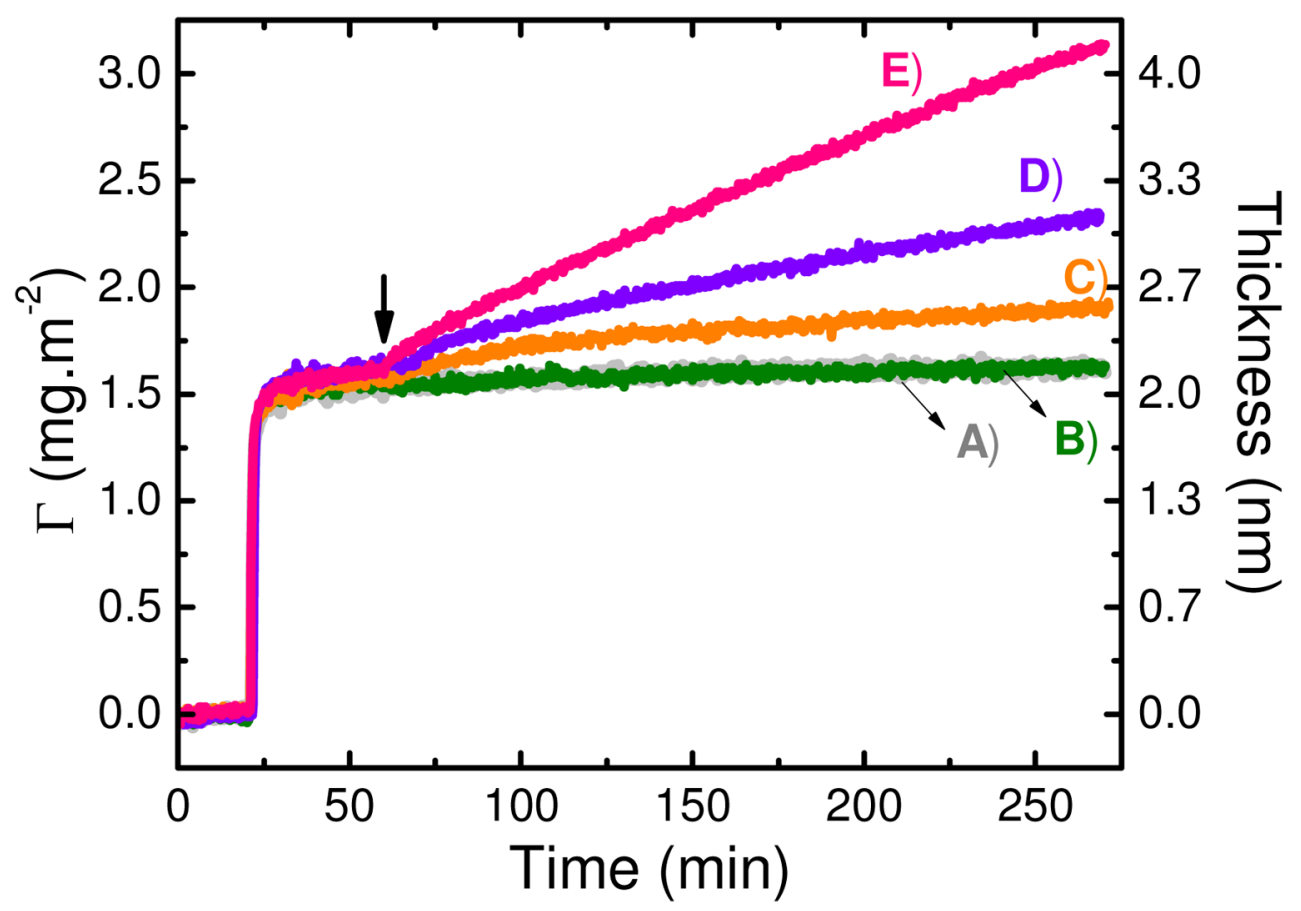

Figure 3.

Effect of applied potential on the dynamic adsorption of $0.50 \mathrm{mg} \cdot \mathrm{mL}^{-1}$ BSA onto a BSA/ OTCE substrate. Adsorption experiments were performed in $10 \mathrm{mmol} \cdot \mathrm{L}^{-1}$ citrate buffer at $\mathrm{pH}=5.7$ with a flow rate of $1 \mathrm{~mL} \cdot \mathrm{min}^{-1}$ at: A) OCP; B) $+500 \mathrm{mV}$; $)+650 \mathrm{mV}$; D) +800 $\mathrm{mV}$; and $\mathrm{E})+950 \mathrm{mV}$. The arrow shows the time when the external potential was applied. 


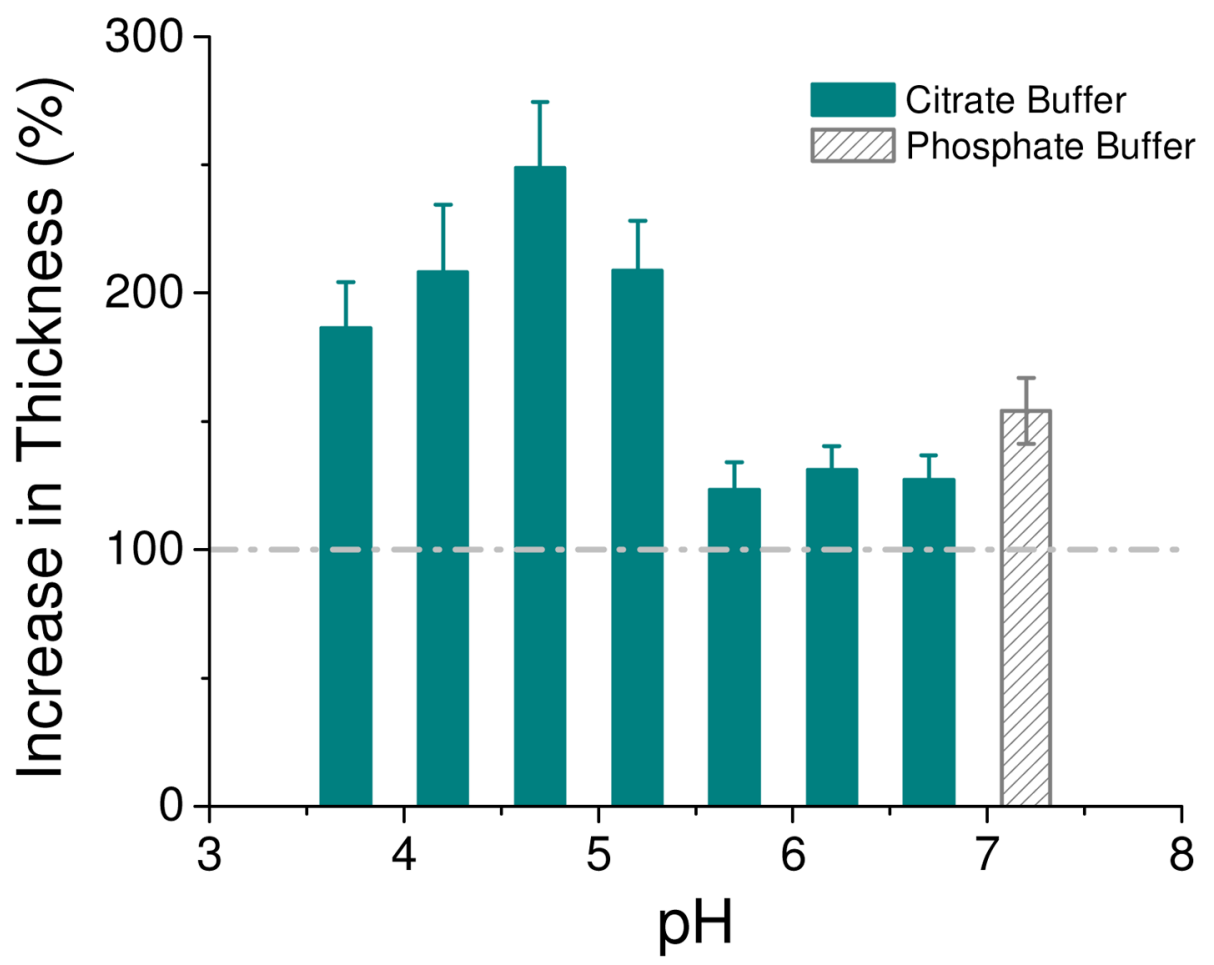

Figure 4.

Effect of $\mathrm{pH}$ on adsorption of $0.50 \mathrm{mg} \cdot \mathrm{mL}^{-1} \mathrm{BSA}$ at $+800 \mathrm{mV}$ after adsorption of a BSA layer $(3.5 \pm 0.7 \mathrm{~nm})$ onto OTCE at OCP and IEP. All experiments were performed in 10 $\mathrm{mmol} \cdot \mathrm{L}^{-1}$ citrate or phosphate buffer and a flow rate of $1 \mathrm{~mL} \cdot \mathrm{min}^{-1}$. 


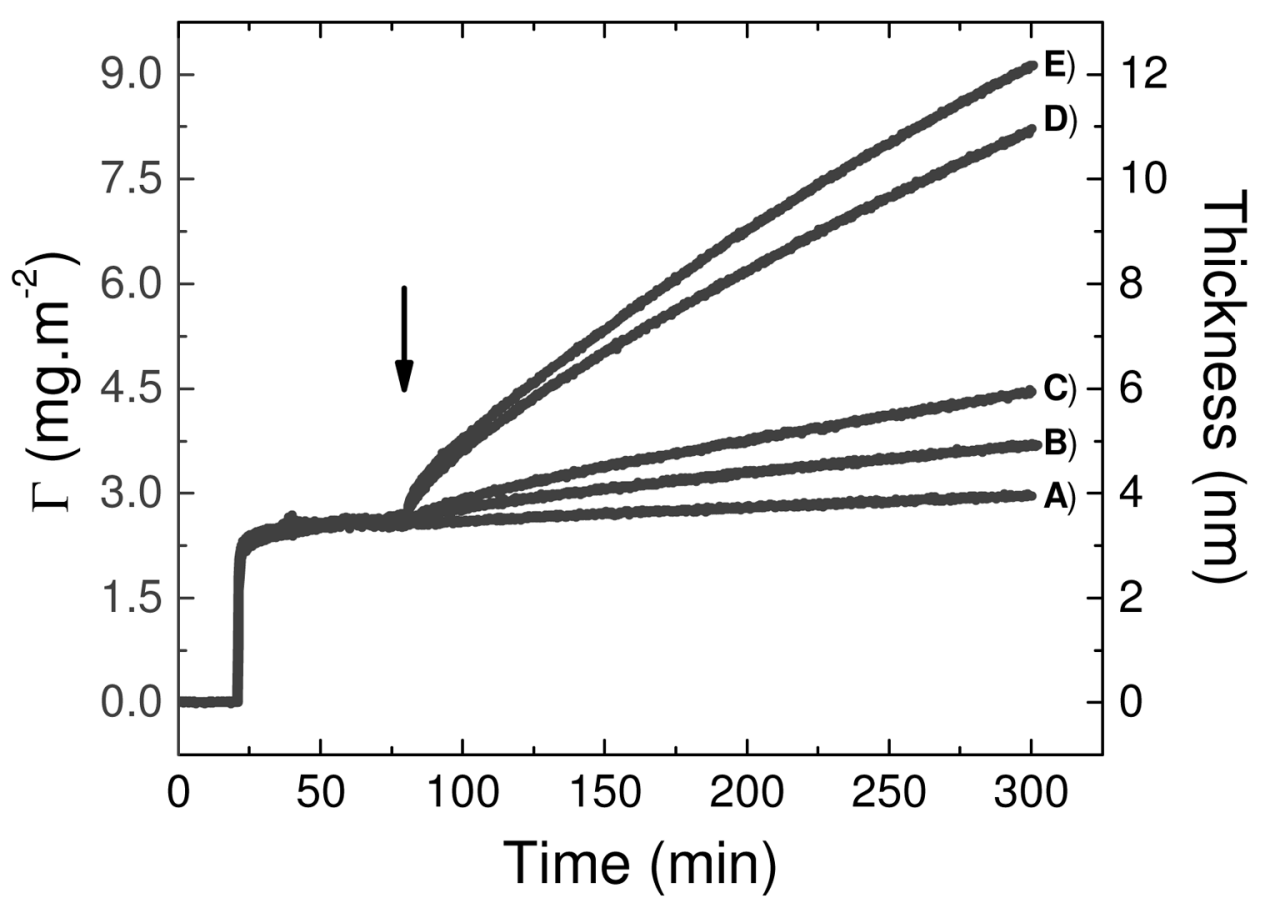

Figure 5.

Effect of BSA concentration on adsorption at $+800 \mathrm{mV}$ of: A) $0.01, \mathrm{~B}) 0.05, \mathrm{C}) 0.10$, D) 0.50 , and E) $1.00 \mathrm{mg} \cdot \mathrm{mL}^{-1}$ after a BSA layer $(3.5 \pm 0.7 \mathrm{~nm})$ was adsorbed onto OTCE at OCP. All experiments were performed in $10 \mathrm{mmol} \cdot \mathrm{L}^{-1}$ citrate buffer at IEP and at a flow rate of $1 \mathrm{~mL} \cdot \mathrm{min}^{-1}$. The arrow shows the time when the external potential was applied. 


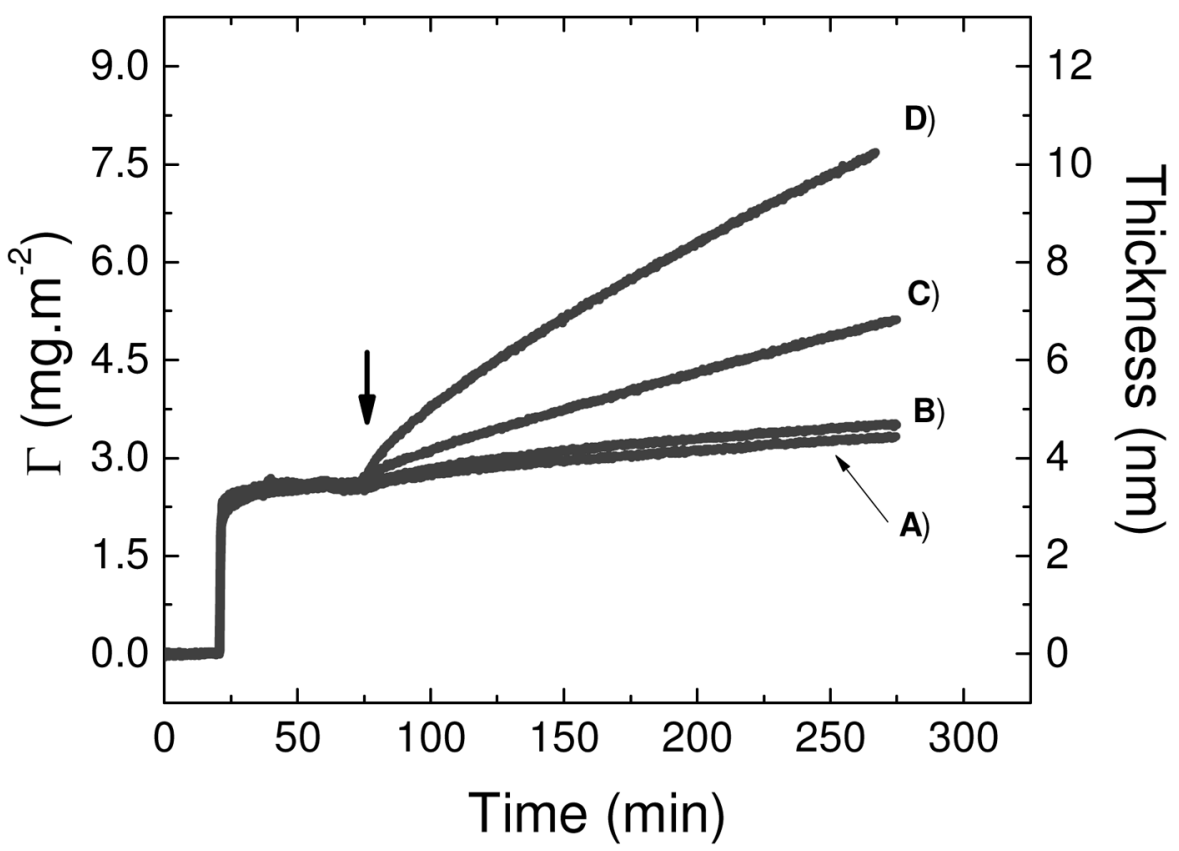

Figure 6.

Dynamic adsorption of BSA $\left(0.50 \mathrm{mg} \cdot \mathrm{mL}^{-1}\right)$ at $+800 \mathrm{mV}$ onto a BSA/OTCE substrate in citrate buffer at $\mathrm{pH}=4.7$ with the addition of $100 \mathrm{mmol} \cdot \mathrm{L}^{-1} \mathrm{NaCl}(\mathrm{A}), 50 \mathrm{mmol} \cdot \mathrm{L}^{-1} \mathrm{NaCl}$ (B), $25 \mathrm{mmol} \cdot \mathrm{L}^{-1} \mathrm{NaCl}(\mathrm{C})$, and no $\mathrm{NaCl}$ (D). The experiments were performed at a flow rate of $1 \mathrm{~mL} \cdot \mathrm{min}^{-1}$. The arrow shows the time when the external potential was applied. 
Open-Circuit Potential

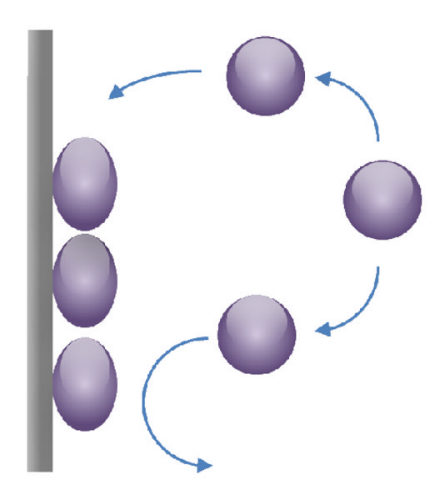

External Potential Applied

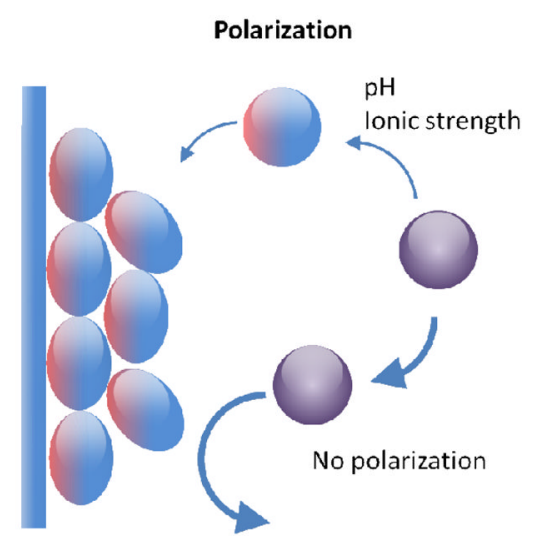

Figure 7.

Schematic representation of the adsorption process of BSA at OCP and in the presence of the external potential. 


\section{Table 1}

Initial adsorption rate (calculated after the corresponding potential was applied, $\mathrm{d} \Gamma / \mathrm{dt}_{1}$ ), linear approximation of the second adsorption process $\left(\mathrm{d} \Gamma / \mathrm{dt}_{2}\right)$, calculated in the 150-250 min interval of the experiment) and final adsorbed amount of BSA onto the BSA/OTCE substrate as a function of the potential applied to the electrode.

\begin{tabular}{|c|c|c|c|}
\hline & $\mathrm{d} \Gamma / \mathrm{dt}_{1}\left(\times 10^{-3} \mathrm{mg} \cdot \mathrm{m}^{-2} \cdot \mathrm{min}^{-1}\right)$ & $\mathrm{d} \Gamma / \mathrm{dt}_{2}\left(\times 10^{-3} \mathrm{mg} \cdot \mathrm{m}^{-2} \cdot \mathrm{min}^{-1}\right)$ & $\Gamma @ 250 \mathrm{~min}\left(\mathrm{mg} \cdot \mathbf{m}^{-2}\right)$ \\
\hline$+500 \mathrm{mV}$ & $1.0 \pm 0.7$ & $0.28 \pm 0.02$ & $1.62 \pm 0.02$ \\
\hline$+650 \mathrm{mV}$ & $6.4 \pm 0.7$ & $0.95 \pm 0.03$ & $1.88 \pm 0.03$ \\
\hline$+800 \mathrm{mV}$ & $14 \pm 2$ & $2.73 \pm 0.02$ & $2.29 \pm 0.03$ \\
\hline +950 mV & $22 \pm 3$ & $6.63 \pm 0.02$ & $3.03 \pm 0.03$ \\
\hline
\end{tabular}

